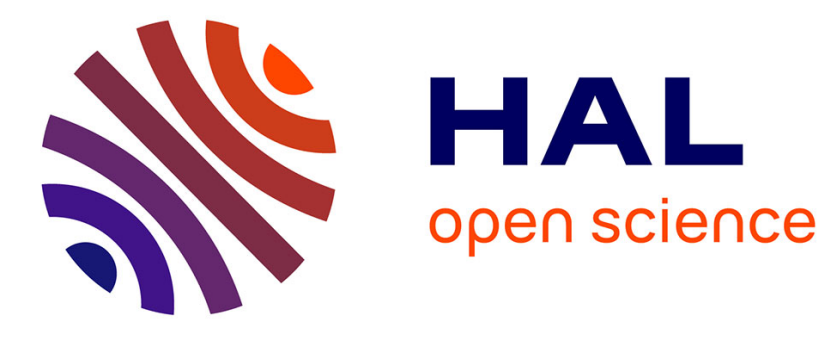

\title{
Friction-induced sheet nacre fracture: effects of nano-shocks on cracks location
}

Philippe Stempflé, Olivier Pantalé, Richard Kouitat Njiwa, Marthe Rousseau, Evelyne Lopez, Xavier Bourrat

\section{- To cite this version:}

Philippe Stempflé, Olivier Pantalé, Richard Kouitat Njiwa, Marthe Rousseau, Evelyne Lopez, et al.. Friction-induced sheet nacre fracture: effects of nano-shocks on cracks location. International Journal of Nanotechnology, 2007, 4 (6), pp.712-729. 10.1504/IJNT.2007.015466 . insu-00181111

\section{HAL Id: insu-00181111 https://hal-insu.archives-ouvertes.fr/insu-00181111}

Submitted on 7 Nov 2007

HAL is a multi-disciplinary open access archive for the deposit and dissemination of scientific research documents, whether they are published or not. The documents may come from teaching and research institutions in France or abroad, or from public or private research centers.
L'archive ouverte pluridisciplinaire HAL, est destinée au dépôt et à la diffusion de documents scientifiques de niveau recherche, publiés ou non, émanant des établissements d'enseignement et de recherche français ou étrangers, des laboratoires publics ou privés. 


\title{
Friction-induced sheet nacre fracture: effects of nano-shocks on cracks location
}

\author{
Philippe Stempflé*, Olivier Pantalé
}

Laboratoire Génie de Production,

ENIT, 47 Avenue d'Azereix,

65016 TARBES Cedex, France,

Fax: +33 (0)5 62442724

E-mail: philippe.stempfle@enit.fr

E-mail: olivier.pantale@enit.fr

${ }^{\star}$ Corresponding author

\section{Richard Kouitat Njiwa}

Laboratoire Science et Génie des Surfaces,

Ecole des Mines, Parc de Saurupt,

54042 NANCY Cedex, France,

Fax: $+33(0) 383584067$

E-mail : kouitat@mines.inpl-nancy.fr

\section{Marthe Rousseau, Evelyne Lopez}

Muséum National d'Histoire Naturelle (UMR 5178 CNRS - MNHN), CP26, 43 Rue Cuvier, 75005 PARIS, France,

Fax: +33 (0)1 40794808

Email : rousseam@gmx.net lopez@mnhn.fr

\section{Xavier Bourrat}

Institut des Sciences de la Terre d'Orléans CNRS,

1A Rue de la Férollerie,

45071 ORLEANS Cedex 2, France,

Fax: +33 (0)238494093

Email : Xavier.Bourrat@univ-orleans.fr

\begin{abstract}
Nacre (the pearly internal layer of molluscan shells) is an attractive nanocomposite displaying high mechanical properties, low density and a good biocompatibility with human bones. It is currently studied for both the prosthesis design and the creation of new organic/inorganic hybrid materials by mimicking biomineralization processes. These exceptional mechanical properties are ascribed to its highly ordered layered 'bricks \& mortar' microstructure and more particularly to the energy absorption ability of the mortar during crack propagation. However, this ability appears to be drastically reduced in presence of nano-shocks generated during friction by the dynamic sollicitations. This paper compares two Finite Element simulations - a quasi-static compression test and a dynamic impact test - in order to consider the fracture mechanisms induced by friction. It reveals that cracks migrate from the mortar to the bricks, involving in the latter case, the formation of wear nano-debris. These numerical results are confronted with experimental results during friction.
\end{abstract}


Keywords: sheet nacre, friction, nanowear, nanoindentation, numerical simulation, dynamic impact test.

\section{Biographical notes:}

Philippe Stempflé is an Assistant Professor in Mechanics and Materials Science at the Engineers School of Tarbes, France and Researcher at the Department of Tribology. He studies the wear mechanisms at the nanoscale by using experimental and numerical approaches. His main results are published in Wear, Tribology Letters, Tribology International, Int. J. of Surface Science and Engineering, and Biomaterials.

Olivier Pantalé is an Assistant Professor in Mechanics at the Engineers School of Tarbes, France and a researcher at the Department of Computer Assisted Mechanics. His main research activities concerns large deformation and non-linear behaviour of material subjected to high dynamic loading and impact, and numerical simulation of machining processes. He has developed a non-linear explicit FEM code and published his main research results in Advances in Engineering Softwares, Computer Methods in Applied Mechanics and Engineering and Journal of Computational and Applied Mathematics.

Richard Kouitat Njiwa is Assistant Professor in Mechanics at the University of Nancy I, France. He is researcher at the "Laboratoire de Science et Génie des Surfaces", and is actually interested in material characterization and damaging under contact load. His research results are published in Surface and Coating Technologies, Engineering Fracture Mechanics, International Journal of Mechanical Science.

Marthe Rousseau has a post-doctoral position in marine biology at the National Museum of Natural History of Paris, France and is a researcher of the BOME CNRS Research Unit. Her main research activities concerns structure and growth mechanisms of molluscan nacre. Her main results are published in Biomaterials, Journal of Structural Biology and Journal of Biomedical Material Research.

Evelyne Lopez is a Professor of the National Museum of Natural History, (PARIS), Director of a Research Team CNRS and Director of the technological research team ERT "Valorisation of sea origin bioactive molecules". She is Biologist, Physiologist, and Endocrinologist. Its specialities are Sea biology, Physiology of the skeleton and of the skin, and Biomineralizations. She is the winner of the Cuvier Academy of Science prize, Commander of the Academic palms and Knight of the Honor Legion. These distinctions reward at the same time her many discoveries, her teaching qualities but also her valorization of research efforts.

Xavier Bourrat obtained his Master degree in Resources, Materials and Minerals of Orleans University in 1980, then his PhD and finally his Habilitation in 1987 at Pau University in Chemistry and Physics of Carbon. He is author or co-author of 5 patents, more than 10 invited lectures, over than 170 papers, chapters or conferences. He received the International Schunk Award '96 for 'Evidence of Disclinations in Mesophase-Pitchbased Carbon Fibers'. He is concerned today with researches in the field of Carbon Cycle, especially 'Biocrystals and carbonate organo-mineral growth processes' as well as 'Refractive carbon sequestration' and also 'Exobiology'. 


\section{Introduction}

Nacre (mother-of-pearl) is a natural nanocomposite studied for the design of new organic/inorganic hybrid materials by mimicking biomineralization processes [1-3]. This biocomposite is generated at ambient temperature and pressure [1] and displays an exceptional high strength $[4,5]$, stiffness [6,7] and toughness [8] compared to others biological ceramic composites [9]. These exceptional mechanical properties are generally ascribed to its peculiar microstructure [10,11] described as a 'bricks and mortar' arrangement [12] (Figure 1). In this configuration, the bricks (97\% in weight) refer to flat crystals of calcium carbonate $\left(\mathrm{CaCO}_{3}\right)$ - in the crystalline form of aragonite - with thickness less than $500 \mathrm{~nm}$; and the mortar (3\% in weight) is an 'intercrystalline' thin network (about $40 \mathrm{~nm}$ ) of a biological organic adhesive - mainly composed of $\beta$-chitin and silk-fibroin-like proteins $[1,7,9]$. Besides, the platelet is itself a nanograin-reinforced organic matrix composite (Fig. 1c) because each aragonite platelet is constituted of $\mathrm{CaCO}_{3}$ nanosized crystals [13,14] surrounded by an 'intracrystalline' organic phase organised as a foam with very thin walls and closed porosity [15-16]. In this paper what is usually described as 'interlamellar' and 'intercrystalline' organic matrix will be call 'intercrystalline' and opposed to 'intracrystalline'.

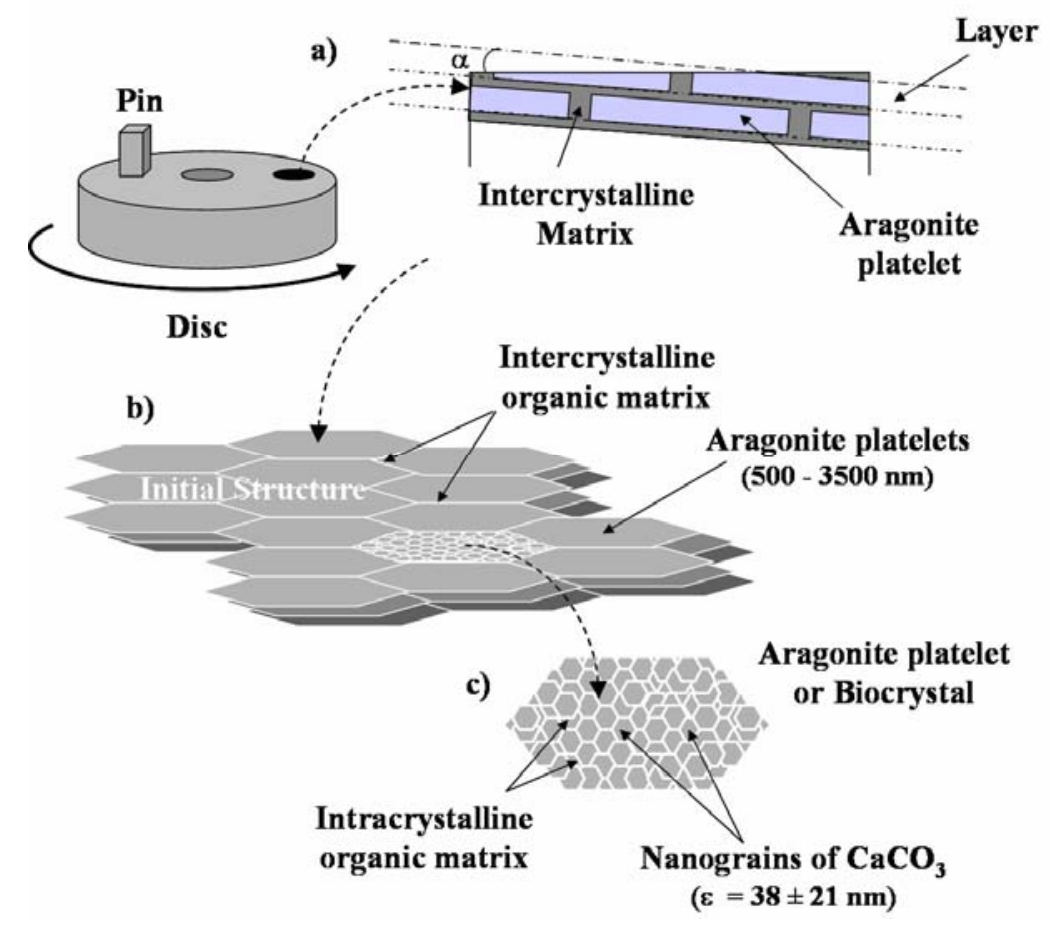

Figure 1 (a) Schematic cross section of the friction surface. Multiscale structure of sheet nacre; (b) aragonite platelets are surrounded by an 'intercrystalline' organic matrix and (c) each platelet is constituted by nanosized CaCO3 crystals (or nanograins) surrounded by an 'intracrystalline' organic phase

The deformation and fracture of sheet nacre have already been studied by many authors using various quasi-static mechanical tests: tension [6], three- and four-point bending 
$[17,18]$, shear $[18,19]$ and microindentation [20]. Although their results reveal the existence of different fracture mechanisms depending on the mechanical stresses (sliding of platelets, formation of organic ligaments between platelets [21], crack deflections, crack blunting, crack branching, crack bridging, micro-crack formation, platelets pull-out, diversion); they necessarily involve the 'intercrystalline' organic matrix surrounding the aragonite platelets. Besides, the cracks remain confined inside the organic matrix - or at the interface with the organomineral platelets - and never pass through the platelet. Hence, platelets are never directly cut in quasi-static mechanical tests.

Recently [22] it has been revealed that the fracture of sheet nacre under friction occurs mainly inside of the organomineral platelets involving the formation of nano-debris (size: $20-35 \mathrm{~nm}$ ) even though the stress level required to fracture the platelets is greater than the one for the matrix [8]. In fact, the main difference between the tribological test and the quasi-static tests (tension, compression, bending...) is the presence of repeated nanoshocks induced by dynamic solicitations.

The aim of this work is then to highlight the effects of these friction-induced nano-shocks on the location of the fracture by using numerical simulations. Two Finite Element models - devoted respectively to quasi-static and dynamic loads - are considered. The mechanical properties of each of sheet nacre's components - i.e organomineral platelets and 'intercrystalline' organic phase - are assessed either experimentally or by a numerical identification from a structural model. For this purpose, AFM image analysis will be a suitable tool for characterizing and modelling the multiscale structure of nacre.

\section{Experimental}

\subsection{Samples}

Samples are made of sheet nacre extracted from giant oyster Pinctada maxima [22]. They are polished more or less parallel to the aragonite platelets $(\mathrm{Ra}=14.5 \pm 0.6 \mathrm{~nm})$. The average size of the initial nanograins as determined by AFM image analysis (cf. section 2.4 ) is $38 \pm 21 \mathrm{~nm}$. The thickness of the 'intracrystalline' matrix is about $4 \mathrm{~nm}$.

\subsection{Nanoindentation}

The mechanical properties of the samples are obtained with a NHT nanoindenter manufactured by CSM Instruments. It is composed of two elements: an instrumented nanoindenter and an optical microscope (enlargements, $\times 50$ and $\times 1000$ ). These elements are linked with an electromechanical positioning system $(\mathrm{X}, \mathrm{Y})$, which allows a relocation of the sample between the indenter and the microscope within a precision of $0.5 \mu \mathrm{m}$. The vertical displacement and loading resolutions are, respectively, $0.03 \mathrm{~nm}$ and $1 \mu \mathrm{N}$. The compliance of the apparatus is $0.25 \mathrm{~nm} \cdot \mathrm{mN}^{-1}$. A $5 \mu \mathrm{m}$ radius spherical diamond indenter is used $\left(E_{i}=1141 \mathrm{GPa}, v_{\mathrm{i}}=0.07\right)$. A minimum of 30 indentations is carried out for each test. 


\subsection{Tribological tests}

We used a pin-on-disc tribotester manufactured by CSM Instruments. The tests are carried out at ambient air and room temperature in dry conditions by repeated friction of a $3.5 \mathrm{~mm}$ square shaped pin of nacre against the surface of a polished disc of nacre $(\varnothing 44$ $\mathrm{mm}$ ). The normal load varies from $1 \mathrm{~N}$ to $6 \mathrm{~N}$ corresponding to a mean contact pressure of $0.1 \mathrm{MPa}$ to $0.5 \mathrm{MPa}$. The speed and the length of sliding are respectively $10 \mathrm{~mm} \cdot \mathrm{s}^{-1}$ and $100 \mathrm{~m}$.

\subsection{AFM and image analysis}

Topography is assessed by using an Atomic Force Microscope Dimension 3000 connected to an electronic controller: Nanoscope IIIa manufactured by Digital Instruments (USA). Its spatial and vertical resolutions are lower than $1 \mathrm{~nm}$ and the field depth in-between $100 \mathrm{~nm}$ and $100 \mu \mathrm{m}$. The micrographs were achieved in high resolution $\left(512 \times 512\right.$ pixels) by using an intermittent contact mode (Tapping Mode ${ }^{T M}$ ), which minimises the interactions between the probe and the surface during the acquisition and largely enhances the resolution compared to the contact-mode [23]. A Phase Detection Imaging (PDI) provides the phase contrast maps which improve the detection of the particles edges during the images analysis [24]. The silicon nitride probe is displaying a tip rounding lower than $10 \mathrm{~nm}$. The work frequency, the stiffness and the cantilever amplitude are respectively: $270 \mathrm{kHz}, 42 \mathrm{Nm}^{-1}$ and $25 \mathrm{~nm}$. According to the size of the images (between $0.25 \mu \mathrm{m}^{2}$ and $25 \mu \mathrm{m}^{2}$ ), the scanning rate varies from $1 \mu \mathrm{ms}^{-1}$ to 2.4 $\mu \mathrm{ms}^{-1}$.

The size, the shape and the volume fraction of biocrystals nanograins were determined, from the phase contrast maps, with a specific algorithm integrated in the SPM data analysis software Gwyddion [25]. Analysis was made from cumulated measurements of at least 5,000 particles (images of $0.25-1 \mu \mathrm{m}^{2}$ ).

\section{Results and Discussion}

\subsection{Tribological tests}

Figure 2(a) contains the plots of the friction force vs. sliding distance for different normal loads. The high disturbance of the curves is due to local nano-shocks resulting from the "natural" structure of sheet nacre (Figure 1). A smoothed version of the above curves is presented in Figure 2(b). They reveal the existence of a run-in period, probably associated with the geometric adaptation of the surfaces. The deduced friction coefficient is rather high - i.e about 0.45 .

Figure 3 shows a typical AFM view of the friction track after $100 \mathrm{~m}$ sliding. It can be observed that the worn surface is strongly degraded by parallel cracks aligned with the structure of sheet nacre. The morphology of these parallel cracks reveals two sorts of typical edge lines: 
- On the one hand (Figure 4), the crack is cut clear. Then, the damage mechanism is clearly a brittle fracture around the aragonite platelets which involves the fracturing inside the 'intercrystalline' organic matrix along the interface between adjacent platelets.

- On the other hand (Figure 5), the crack edges are rough and strongly disturbed. The damage is a kind of crumbling of the aragonite platelets. In this case, the fracture is supposed to occur inside the platelets itself and involves the fracturing of the 'intracrystalline' organic matrix.
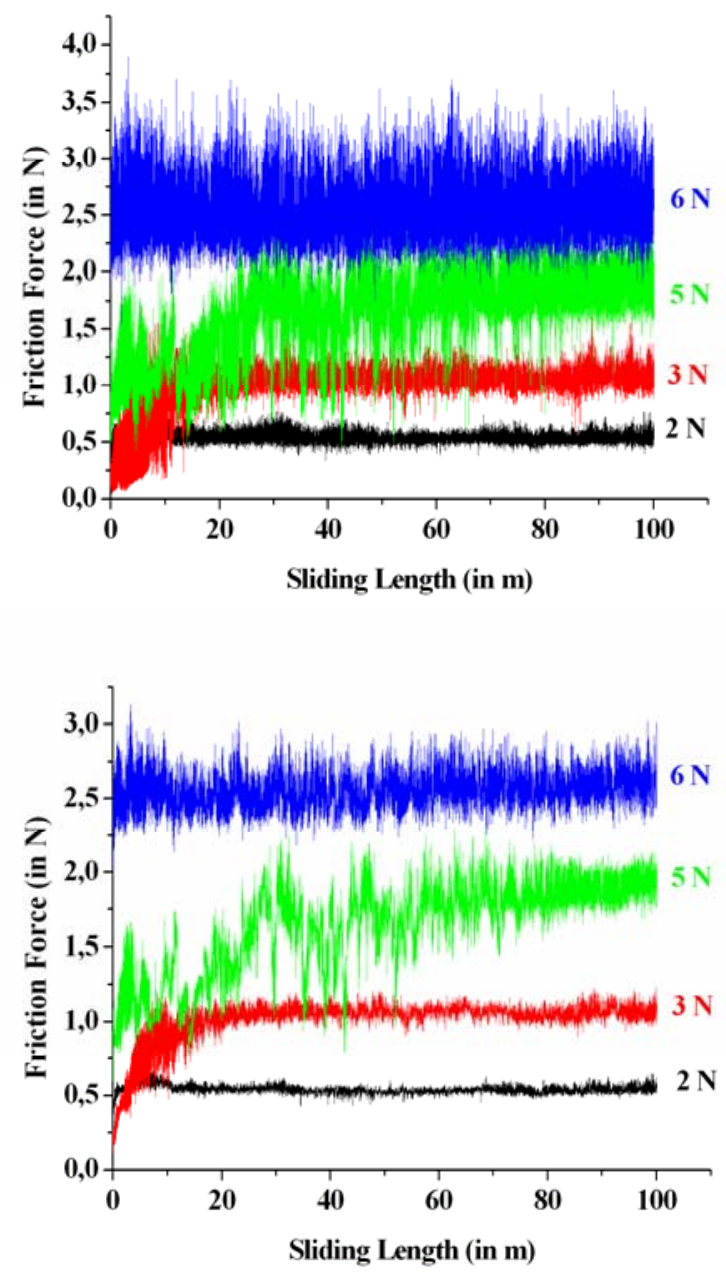

Figure 2 Variations of the friction force with the sliding length for various applied loads: (a) raw data and (b) smoothed with a 10 points adjacent averaging algorithm (for colours see online version) 

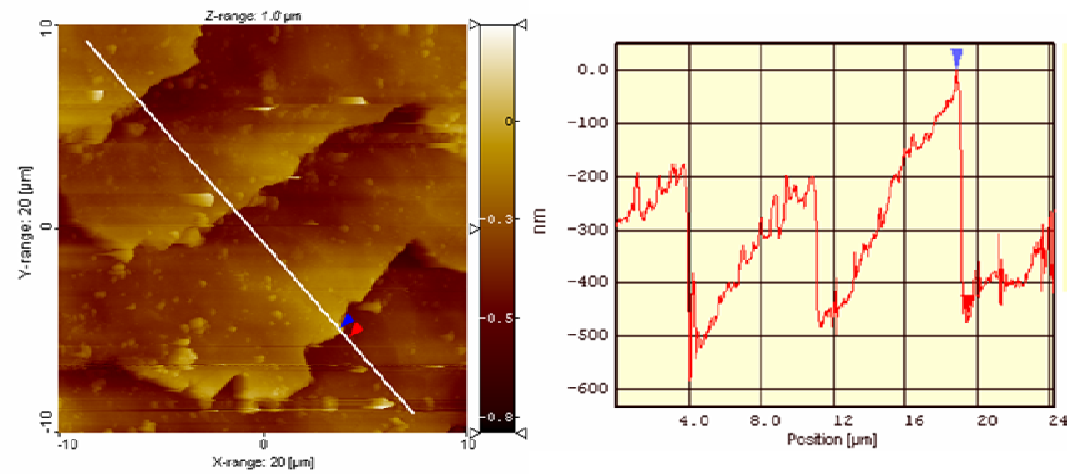

Figure 3 Typical AFM view $\left(20 \times 20 \mu m^{2}\right)$ and topographic profile of the friction track (for colours see online version)
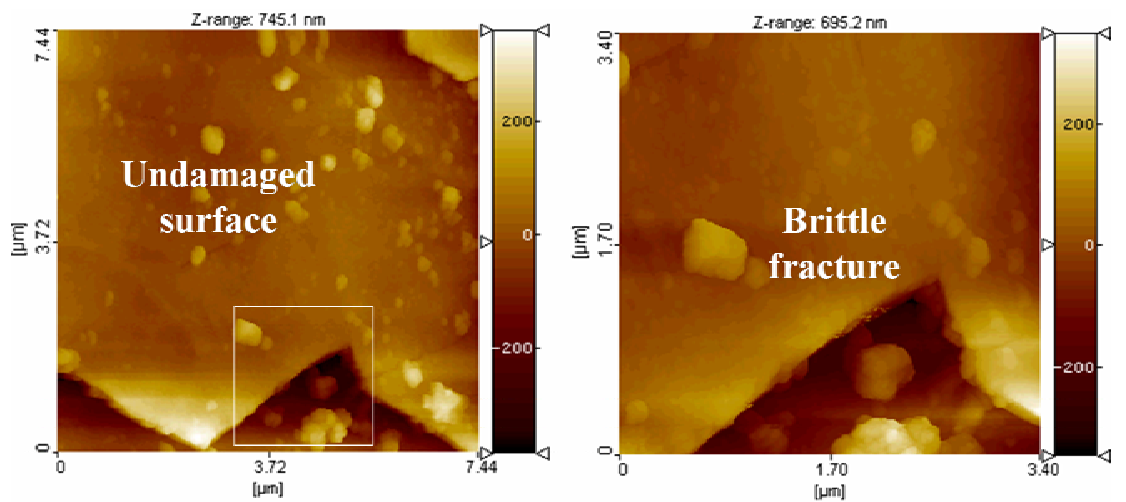

Figure 4 Typical AFM views of the morphology of the edge line in the case of the brittle fracture

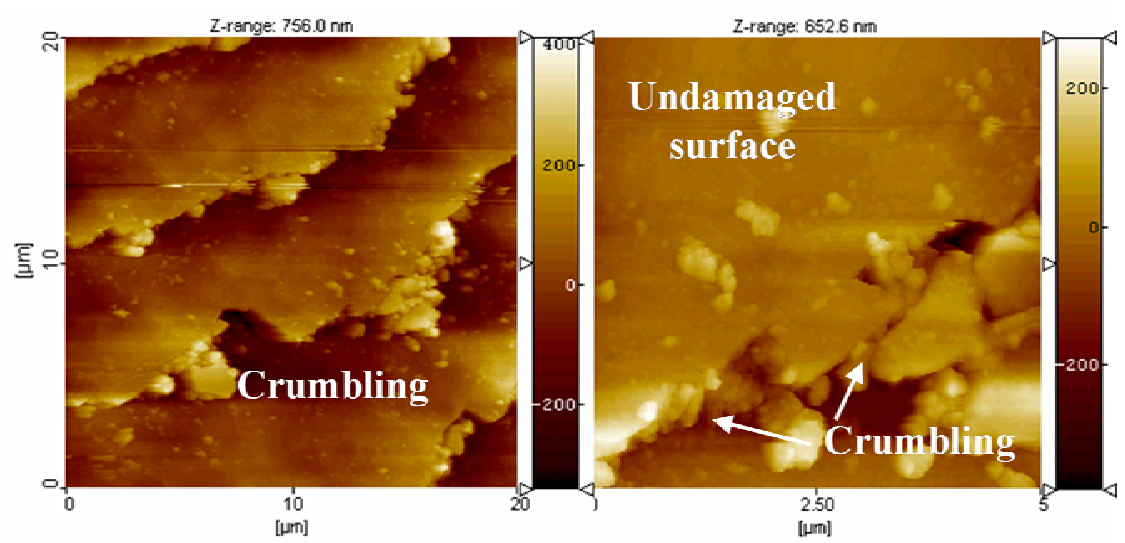

Figure 5 Typical AFM views of the morphology of the edge line in the case of crumbling

Although frequently reported in the case of quasi-static mechanical tests [26-34], the first mechanism is rarely observed after friction because it is generally followed by the 
platelet fragmentation [22]. Thus, this second mechanism (Figure 5) appears to be the main damage mechanism observed after sliding.

A Finite Element Analysis should enable to understand this particular friction-induced fracture mechanism. The required mechanical parameters of nacre's components $-i$.e the organomineral platelet and the "intercrystalline" organic phase - are determined by nanoindentation.

\subsection{Nanoindentation of organomineral platelets}

Figure 6 shows the load-depth indentation curves obtained with a $5 \mu \mathrm{m}$ radius indenter for $2 \mathrm{mN}$ maximal load. Within this range of deformation a purely elastic behaviour of platelets may be assumed. As the curves are slightly disturbed, the standard analysis methods $[35,36]$ are not really suitable. Hence, a Hertzian contact analytical solution is fitted onto the experimental curves in order to determine the Young's modulus (Figure 7). The average value identified from the whole tests is : $\mathrm{E}=62.49 \pm 11.26 \mathrm{GPa}$.

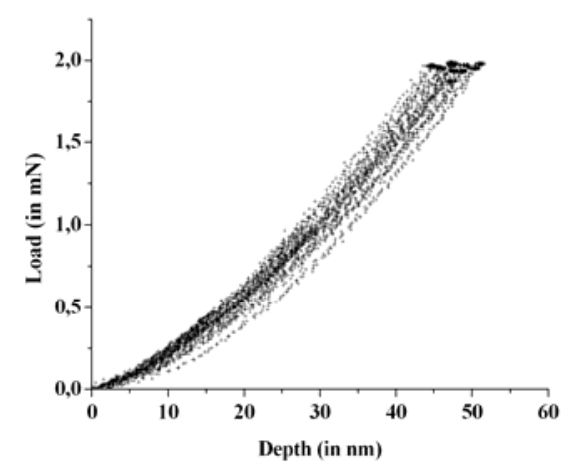

Figure 6 Experimental load-depth curves performed on aragonite platelets at low loads

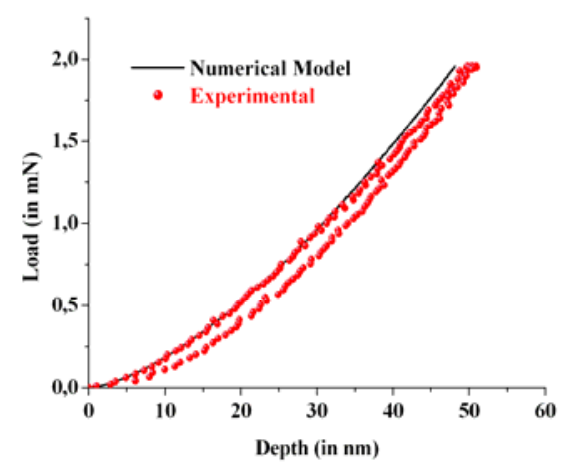

Figure 7 Typical load-depth curve and numerical Hertzian model allowing the identification of elastic mechanical properties of aragonite platelets

Figure 8 shows the load-depth curves obtained for $10 \mathrm{mN}$ maximal load. At this load, a dissipative component is clearly observed under the load-depth curves. As shown in the 
inset (Figure 8), the dissipative component corresponds to a plastic deformation involving piling-up phenomena. Hence, the previous Hertzian model enables to extract the limit of the elastic domain $-i . e$ the compressive yield stress (about $\sigma_{\mathrm{y}}=2.7 \pm 0.4 \mathrm{GPa}$ ).

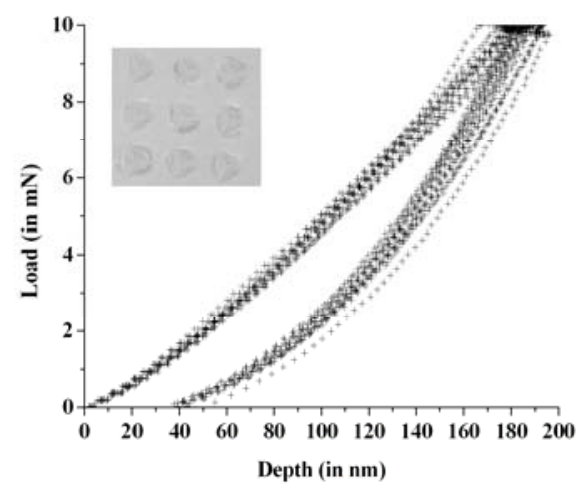

Figure 8 Experimental load-depth curves performed on aragonite platelets at high load. Inset spherical imprints after tests

When the normal load is pushed up to $20 \mathrm{mN}$, the penetration depth becomes higher than $300 \mathrm{~nm}$ and the contribution of the "intercrystalline" matrix is clearly observed. The Young's modulus decreases from 62.5 to $54.4 \mathrm{GPa}$, corresponding to the Young's modulus of the nanocomposite - i.e., platelets + "intercrystalline" organic phase $(\mathrm{E}=$ $54.42 \pm 3.27 \mathrm{GPa})$.

Beyond $20 \mathrm{mN}$, the mechanical properties stay constant (about 54.5 GPa).

\subsection{Properties of the "intercrystalline" organic matrix}

Knowing the mechanical properties of the organomineral platelets $(62.5 \mathrm{GPa})$ and the nanocomposite $(54.4 \mathrm{GPa})$, the mechanical properties of the "intercrystalline" organic phase could be drawn from a structural model. According to Rousseau et al. [15,16], the Pinctada maxima sheet nacre does not present mineral bridges between the platelets. The "intercrystalline" matrix is then continuous. Hence, it can be considered in a first approximation (Figure 9) that the Young's modulus - assessed at high loads spherical nanoindentation - corresponds in fact to the transversal Young's modulus $\left(E_{T}\right)$ of a stacking of layers made up of pure matrix and reinforced layers (mineral and organic).

This transversal Young's modulus is given by the relation [37]:

$$
E_{T}=\left(\frac{1}{E_{f}-E_{m}\left(1-\frac{1}{\sqrt{V_{f}}}\right)}+\frac{1-\sqrt{V_{f}}}{E_{m}}\right)^{-1}
$$

where $E_{f}$, and $E_{m}$ are respectively the Young's modulus of the platelets and the "intercrystalline" organic matrix. $V_{f}$ is the volume fraction of the platelets, considering nacre as a composite of platelets and "intercrystalline" organic matrix. This relation 
provides a good approximation of the Young's modulus of the matrix $\left(E_{m}\right)$ as a function of $E_{f}$ and $E_{T}$, determined by nanoindentation respectively using low and high loads.

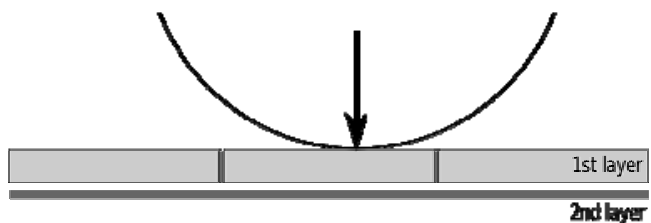

Figure 9 Illustration of the model used for identifying elastic properties of the 'intercrystalline' matrix (dark grey) vs. those of the platelet (light grey)

Results show that the "intercrystalline" organic matrix Young's modulus is ten times lower than that of the aragonite platelets (Table 1).

Table 1 Identified Young's modulus of the "intercrystalline" organic matrix

\begin{tabular}{cccc}
\hline$E_{T}(G P a)$ & $E_{f}(G P a)$ & $V_{f}$ & $E_{m}(G P a)$ \\
\hline 54.424 & 62.489 & 0.97 & 6.308 \\
\hline
\end{tabular}

Knowing the mechanical properties of the different components of sheet nacre, a Finite Element analysis is now used in order to understand the specific fracture processes induced by friction. The main difference between the tribological and quasi-static tests is the presence of repeated nano-shocks induced by dynamic solicitations. Therefore, two numerical models will be compared in order to reveal the effects of these nano-shocks on the fracture location.

\subsection{Numerical Simulation}

\subsubsection{Numerical models used for FEM simulations}

The first numerical model simulates a quasi-static compression test of a sheet nacre specimen while the second one simulates the effect of a rigid impactor on the sample. The damage mechanism associated with both tests is analysed and correlated to the results of tribological tests. The Abaqus Explicit FEM code [38] is used to solve both problems. The choice of an explicit code is linked to the presence of severe nonlinearities induced both by the large deformations and the behaviour laws used.

Figure10 shows the main characteristics of both models:

- The inclination angle of $8^{\circ}$ between the impactor trajectory and the platelets has been evaluated using the AFM facility on the specimens used for the tribological tests (Figure 3).

- In both numerical simulations, the rigid impactor is moved with a prescribed velocity of $10 \mathrm{~mm} \cdot \mathrm{s}^{-1}$ - corresponding to the relative tribological test velocity.

- Contact between the impactor and the sheet nacre specimen is assumed to be frictionless and without any influence on the results because contacting surfaces exhibit only a normal relative displacement during simulation. 
- 6800 and 4100 elements are used in both models respectively. The "intercrystalline" organic matrix is meshed using two elements of $12.5 \mathrm{~nm}$ thickness.

- All displacements have a prescribed value of zero for the left and bottom edges in both models.

- From one model to the other one, only the boundary conditions linked to the rigid impactor vary as it will be detailed further.

- To simulate the fracture inside both materials, a ductile damage law based on the maximal equivalent plastic strain value $\left(\varepsilon_{\max }\right)$ is used.

- This damage law is coupled with the erosion algorithm of the Abaqus Explicit code: when the ductile damage criterion is reached, the corresponding element is considered instantly completely damaged, and is removed from the FE model. Only the initiation part of this damage law is used in the simulations.

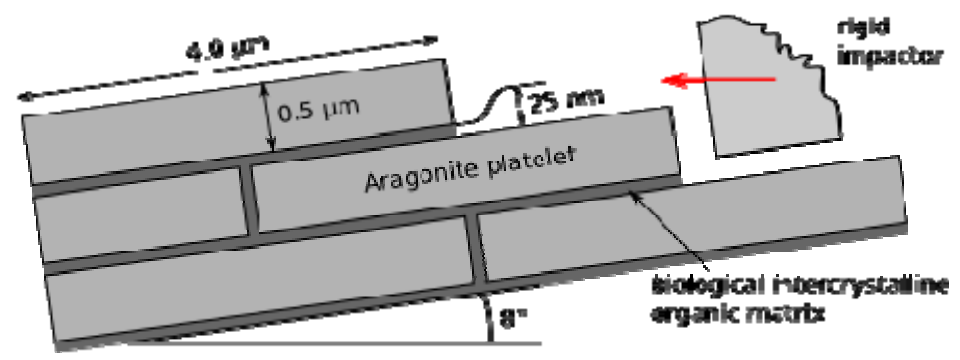

Figure 10 Geometrical description of the models used for both numerical simulations

The maximum strain value $\left(\varepsilon_{\max }\right)$ of the "intercrystalline" organic phase $(10 \%)$ is extracted from the work of Ji and Gao [10].

Concerning the organomineral platelet, the plastic deformation is assumed to be controlled by the "intracrystalline" organic matrix surrounding the $\mathrm{CaCO}_{3}$ nanograins (see Figure 11). Therefore, the maximum strain value of the platelet is estimated from the volume fraction of the organic matrix, within the platelet, measured by AFM image analysis - about $12 \%$ in $2 \mathrm{D}$ corresponding to $4.2 \%$ in $3 \mathrm{D}$. This value is close to those obtained by biological extractions [39]. Therefore, the previously unknown maximum strain value $\varepsilon_{\max }$ of the platelets has been estimated to be about $12 \%$ of the one of the "intercrystalline" organic matrix $\left(\varepsilon_{\max }=10 \%\right)$ because both presented models are bidimensionnal ones.

Material mechanical properties used in both simulations are compiled in Table 2.

Table 2 Identified mechanical properties (a) from Ji and Gao [10])

\begin{tabular}{ccccc}
\hline & $E(\mathrm{GPa})$ & $\sigma_{y}(\mathrm{GPa})$ & $v$ & $\varepsilon_{\max }(\%)$ \\
\hline$[\mathrm{A}]$ & 62.5 & 2.5 & 0.2 & 1 \\
{$[\mathrm{M}]$} & 6.3 & 0.116 & 0.3 & $10^{a)}$ \\
\hline
\end{tabular}




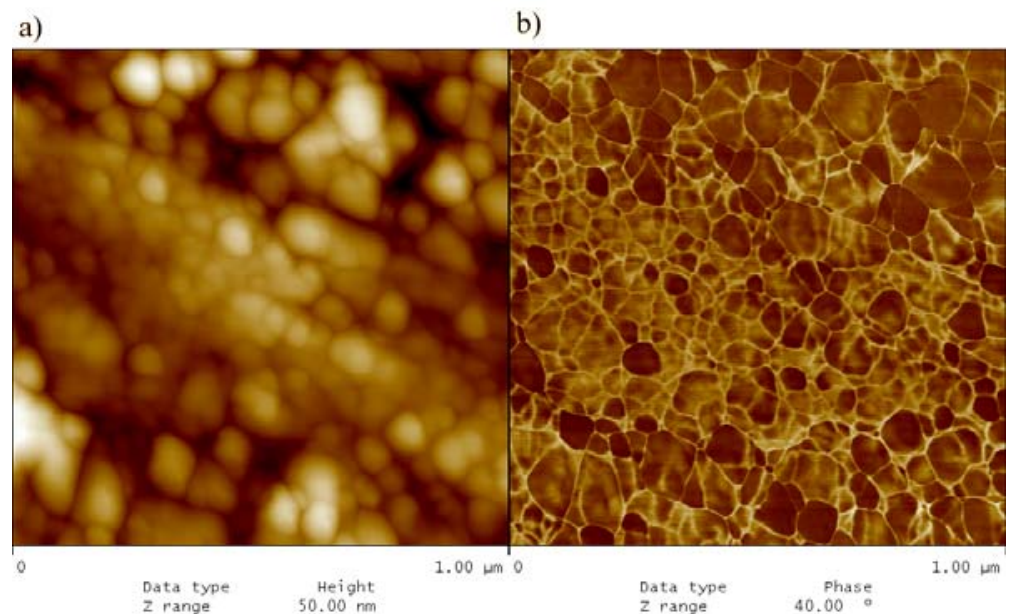

Figure 11 Typical AFM views of the polished surface of an aragonite platelet observed in tapping-mode topographic (a) and phase contrast maps (b) revealing the nanosized grains of CaCO3 surrounded by the 'intracrystalline' organic matrix (for colours see online version)

\subsubsection{Quasi-static compression test}

The initial contact length between the aragonite platelet and the rigid impactor is $100 \mathrm{~nm}$ - i.e. $20 \%$ of the total platelet height. The contact zone contains two elements. An initial velocity equal to the impactor velocity is applied to all nodes of the contacted platelet in order to suppress the shock component at the beginning of the simulation. The velocity direction is parallel to the aragonite platelets arrangement.

Figure 12 shows the von Mises contourplot for a total displacement $d=30 \mathrm{~nm}$ of the rigid impactor. It can be observed that the "intercrystalline" organic matrix is completely fractured while the platelet remains intact after deformation and becomes free. This is not surprising because the mechanical properties (Table 2), and more precisely the yield stress $\sigma_{y}$ of the platelet [A] are higher than that of the biological "intercrystalline" organic matrix $[\mathrm{M}]$. The same results have been obtained in traction. Hence, results from quasi-static tests, lead to the conclusion that high shear region and crack propagation may only be located inside of the organic matrix as already reported by both the experimental $[4-9,11,17-20,26-33]$ and other numerical works [10, 32, 40-42].

Note that, the explicit integration algorithm allows us to obtain the complete fracture of the organic matrix without rigid body problems. Fracture lines within nacre are clearly represented by the use of the erosion algorithm coupled with the damage law. 


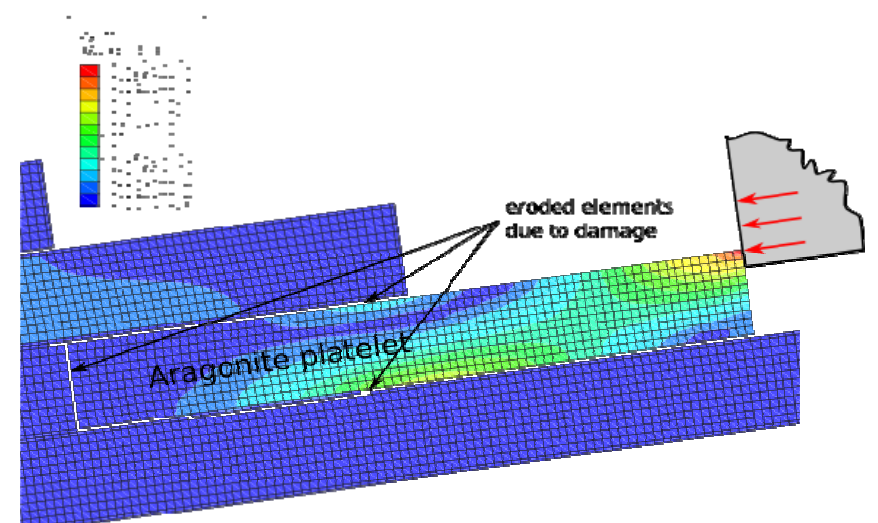

Figure 12 Von Mises contourplot for the quasi-static compression test at the end of the fracture process (for colours see online version)

Figure 13 reports the time-history evolution of the von Mises stresses at four selected points within the "intercrystalline" organic matrix during the simulation. The von Mises stress level increases from zero up-to the yield stress $\sigma_{y}$ for all selected points. When the damage criterion is reached, due to accumulation of plastic deformation, the element is deleted from the computation process and the stress vanishes. During the simulation, the number of viable elements surrounding the platelet decreases as the stress inside of the organic matrix increases. Oscillations observed on the time-history curves of the points farther from the contact zone are purely numerical and due to the removing of elements algorithm. Crack initiates at point $A$ and propagates through points $B, C$ and $D$ respectively.
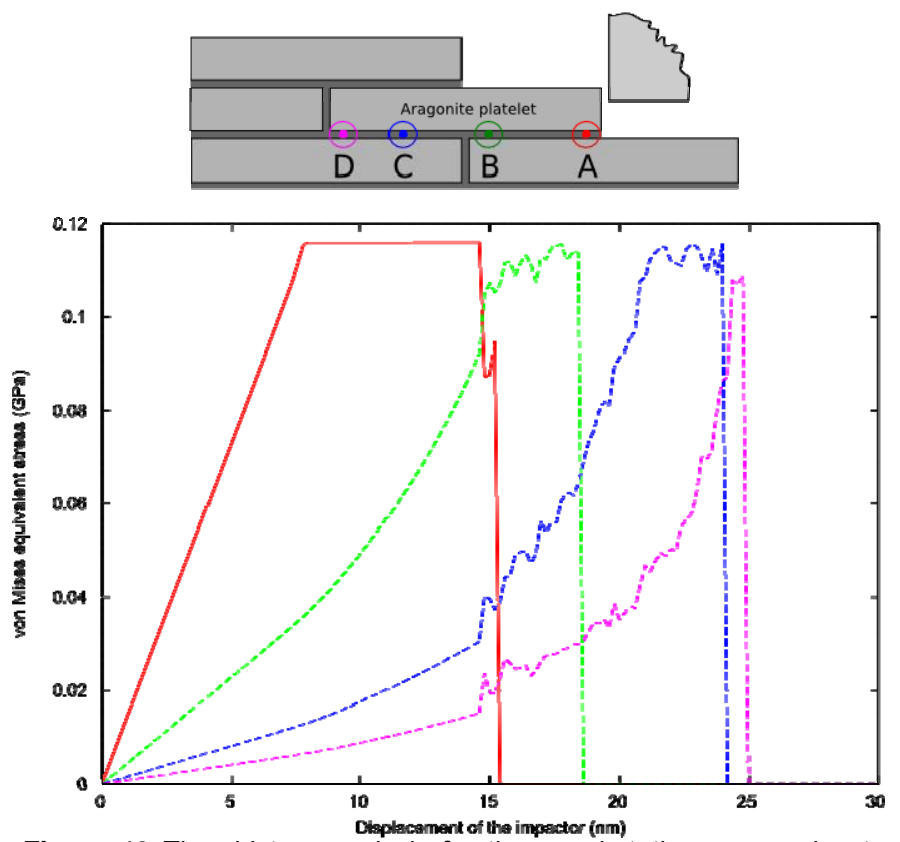

Figure 13 Time-history analysis for the quasi-static compression test (for colours see online version) 


\subsubsection{Dynamic impact test}

The initial contact length between the aragonite platelet and the impactor is now $50 \mathrm{~nm}$. The mesh has been refined locally in order to keep at least two elements in the contact zone. The retained approach is similar to the one proposed by Pantale et al. [43] for the numerical simulation of a machining process.

Figure 14 shows the von Mises stress contourplot for a total horizontal displacement $d=$ $125 \mathrm{~nm}$ of the impactor after the first contact with the platelet. Numerical results show a concentrated region of high stresses in the vicinity of the contact zone between the impactor and the platelet as reported in [43]. As a main consequence of the dynamic effects, and the presence of repeated shocks, the fracture zone illustrated in Figure 14 is totally different from the one reported in Figure 12. Major part of the fracture is now located inside of the aragonite platelet, in accordance with experimental observations using tribological tests. Stress distribution, reported in Figure 14, shows that during the impact, the ratio between the equivalent stress and the yield stress $\left(\bar{\sigma} / \sigma_{y}\right)$, inside of the biological "intercrystalline" organic matrix, is lower than the one inside of the platelet. Therefore, fracture propagation inside of the "intercrystalline" organic matrix is limited and platelet debonding does not occur as in the previous simulation.

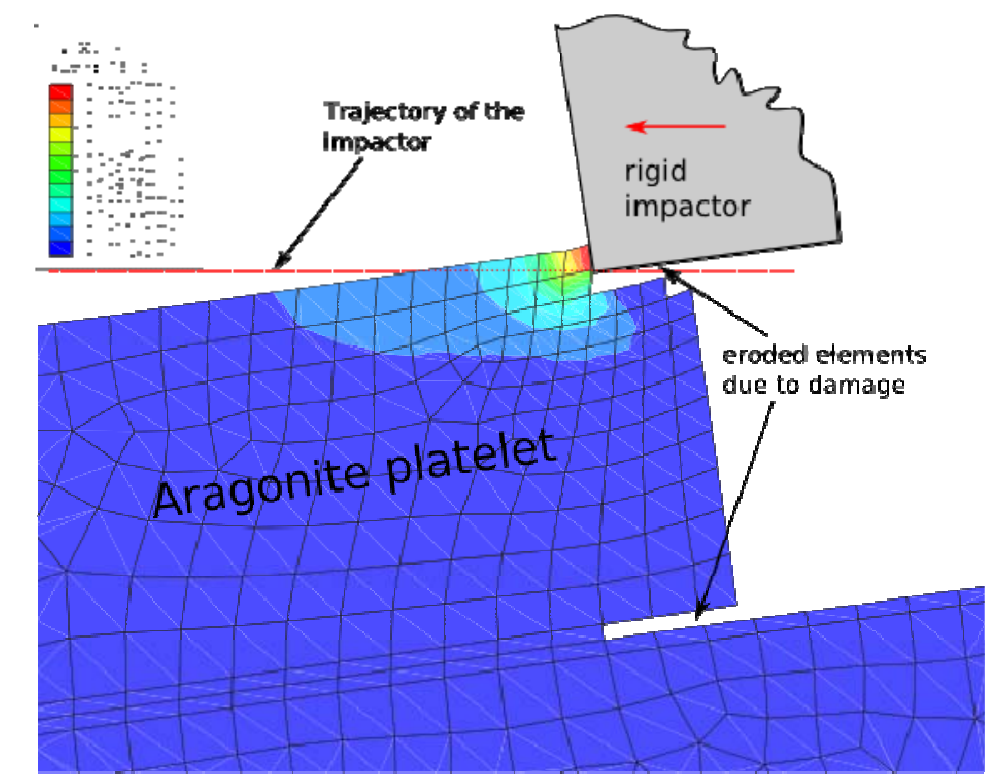

Figure 14 von Mises contourplot for the impact test for a total displacement $d=125 \mathrm{~nm}$ (for colours see online version)

Different simulations have shown that the ratio between the numbers of fractured elements inside of the platelet and inside of the organic matrix increases with decreasing height of the contact zone - i.e when the shearing depth decreases. This usually occurs in tribological tests.

Figure 15 shows the time-history evolution of the von Mises stress for three selected elements $A, B$ and $C$ above the trajectory of the impactor during the simulation. These three points correspond respectively to the second, the sixth and the tenth element 
removed during the simulation. The analysis of the time-history plot in Figure 15 shows that the equivalent von Mises stresses for the three selected points increases linearly for a displacement up-to $d=11.5 \mathrm{~nm}$ - i.e the instant when the damage criterion is reached in the first element. Then, as the first element is removed from the computation, the stress level vanishes until the impactor reaches the second element (element $A$ ). Then, the stress level increases in element $A$ until the damage criterion is reached and the element is removed. The process is repeated during all the simulation, as represented in Figure 15.
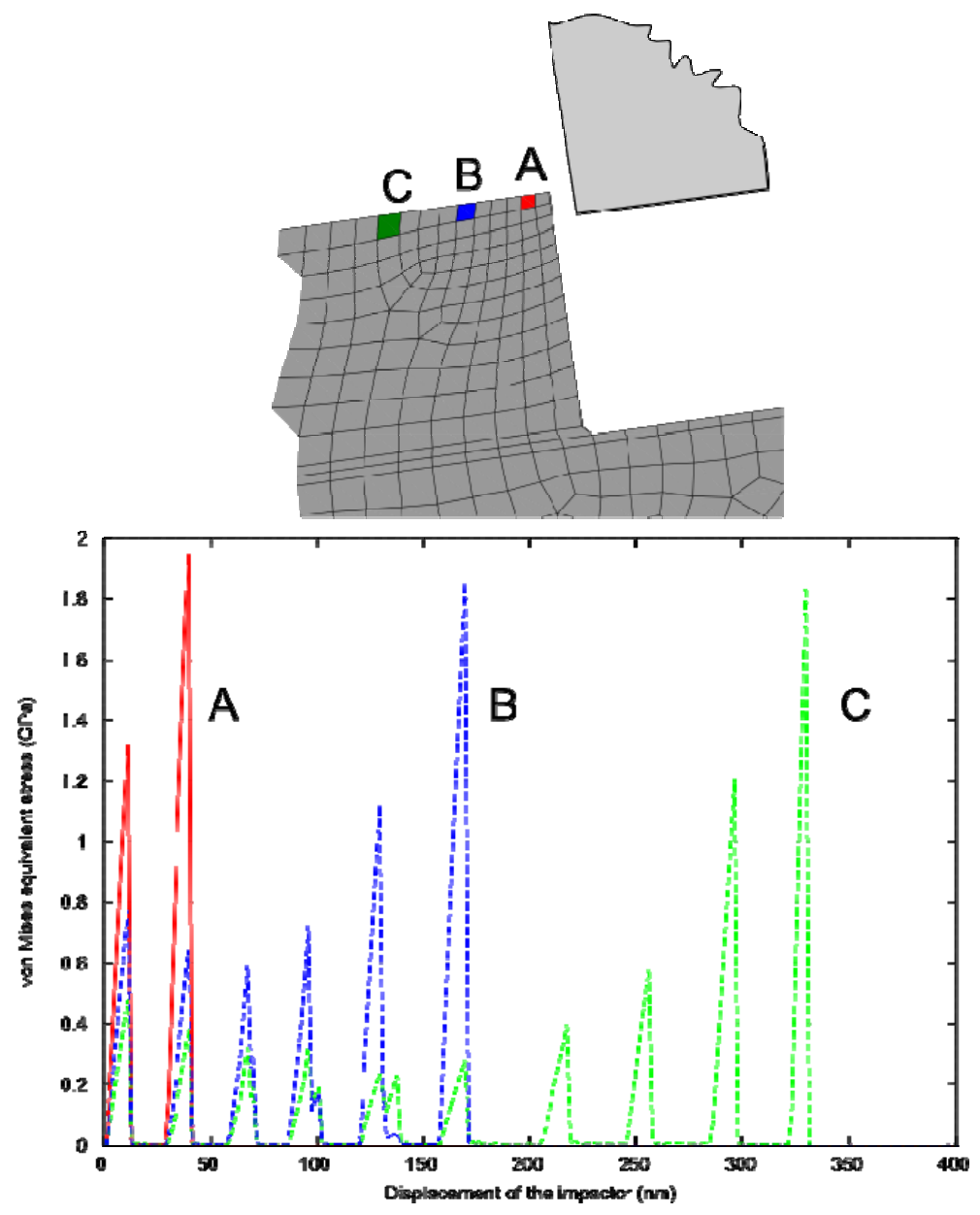

Figure 15 Time-history analysis for the impact test (for colours see online version)

Thus, stress peaks (Figure 15) enable to satisfactorily explain the formation of nanometric wear debris - observed by AFM on the friction track (Figure 16) - which have a size very close to the initial nanograins constituting the platelets - about $40 \mathrm{~nm}$ (Figure 11). Hence, friction-induced nano-shocks seem to be responsible of possible nanoscale wear mechanism. 

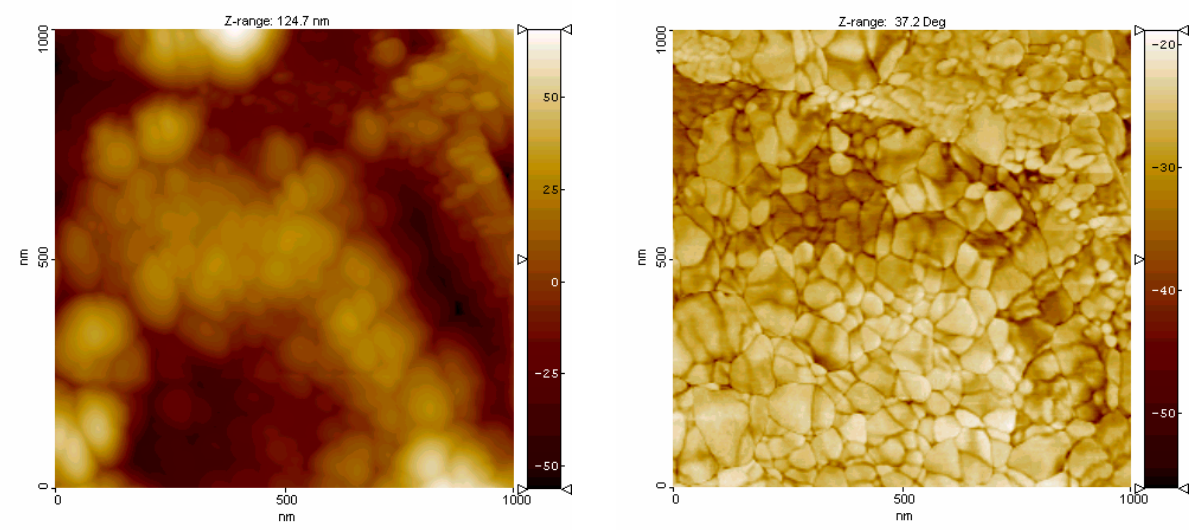

Figure 16 Typical view $(1 \times 1 \mu \mathrm{m})$ of the wear nano-debris observed on the friction track: (a) height and (b) phase (for colours see online version)

\section{Conclusion}

In order to consider the fracture mechanisms induced by friction and more particularly the location of the fracture inside the nanocomposite sheet nacre, this paper compares two Finite Element models: a quasi-static compression test and a dynamic impact test. Results reveal the following:

- in quasi-static mechanical tests (traction, compression, bending, shearing), high shear and crack propagation may only be located inside the 'intercrystalline' organic matrix

- in impact tests, repeated shocks induced by a dynamic effect modify the location of fracture: cracks are observed inside the mineral platelets instead of the 'intercrystalline' matrix.

Since tribological tests also involve nano-shocks, these results rationalize the formation of wear nano-debris generated by the fracture of the mineral platelets. Thus, in dry friction, the wear behaviour is not only controlled by the 'intercrystalline' but also by the 'intracrystalline' organic phase surrounding the $\mathrm{CaCO}_{3}$ nanograins.

\section{Acknowledgments}

Authors wish to thank C. Poigneau from SIERA SA for having supplied them with the nacre samples.

\section{References}

1 Weiner, S. and Addadi, L. (1997) J. Mater. Chem., Vol. 7, No. 5, pp.689-702.

2 Vincent, J.F.V. (2006) in Bar-Cohen, Y. (Ed.): Biomimetics, Biologically Inspired Technologies, CRC Taylor \& Francis, pp.341-363, ISBN 10: 0-8493-3163-3 ISBN 13: 978-0-8493-3163-3. 
3 Carlson, J., Ghaey, S., Moran, S., Tran, C.A. and Kaplan, D.L. (2006) in Bar-Cohen, Y. (Ed.): Biomimetics, Biologically Inspired Technologies, CRC Taylor \& Francis, pp.365-379, ISBN 10: 0-8493-3163-3 ISBN 13: 978-0-8493-3163-3.

4 Currey, J.D. and Taylor, J.D. (1974) J. Zool. London, Vol. 173, pp.395-406.

5 Currey, J.D. (1976) J. Zool. London, Vol. 180, pp.445-453.

6 Currey, J.D. (1977) Proc. R. Soc. London, B, Vol. 196, pp.443-463.

7 Sarikaya, M. and Aksay, I.A. (1992) in Case, S.T. (Ed.): Biopolymers, Springer, Berlin, pp.1-26.

8 Okumura, K. and de Gennes, P.G. (2001) Eur. Phys. J. E, Vol. 4, pp.121-127.

9 Jackson, A.P, Vincent, J.F.V. and Turner, R.M. (1990) J. Mater. Sci., Vol. 25, pp.3173-3178.

$10 \mathrm{Ji}, \mathrm{B}$. and Gao, H. (2004) J. Mech. Phys. Solids, Vol. 52, pp.1963-1990.

11 Neves, N.M. and Mano, J.F. (2005) Mater. Sci. Eng., C, Vol. 25, No. 2, pp.113-118.

12 Addadi, L. and Weiner, S. (1997) Nature, Vol. 389, pp.912-913.

13 Li, X.D., Chang, W.C., Chao, Y.J., Wang, R.Z. and Chang, M. (2004) Nano Lett., Vol. 4 ,

pp.613-617.

14 Li, X., Xu, Z-H. and Wang, R. (2006) Nano Lett., Vol. 6, No. 10, pp.2301-2304.

15 Rousseau, M., Bourrat, X., Stempflé, Ph., Brendlé, M. and Lopez, E. (2005) Key Eng. Mater., Vols. 284-286, pp.705-708.

16 Rousseau, M., Lopez, E., Stempflé, Ph., Brendlé, M., Franke, L., Guette, A., Naslain, R. and Bourrat, X. (2005) Biomaterials, Vol. 26, No. 31, pp.6254-6262.

17 Jackson, A.P., Vincent, J.F.V. and Turner, R.M. (1988) Proc. R. Soc. London, B, Vol. 234, pp.415-440.

18 Wang, R.Z., Suo, Z., Evans, A.G., Yao, N. and Aksay, I.A. (2001) J. Mater. Res., Vol. 16 No. 9, pp.2485-2493.

19 Menig, R., Meyers, M.H., Meyers, M.A. and Vecchio, K.S. (2000) Acta Mater., Vol. 48, pp.2383-2398.

20 Wang, R.Z., Wen, H.B., Cui, F.Z., Zhang, H.B. and Li, H.D. (1995) J. Mater. Sci., Vol. 30, pp.2299-2304.

21 Smith, B.L., Schäffer, T.E., Viani, M., Thompson, J.B., Frederick, N.A., Kindt, J., Belcher, A., Stucky, G.D., Morse, D.E. and Hansma, P.K. (1999) Nature, Vol. 399, pp.761-763.

22 Stempflé, Ph. and Brendlé, M. (2006) Tribology International, Vol. 39, pp.1485-1496.

23 Aimé, J.P., Boigard, R., Nony, L. and Couturier, G. (2001) J. Chem. Phys., Vol. 114, No. 11, pp.4945-4954.

24 Magonov, S.N., Elings, V. and Wangbo, M-H. (1997) Surf. Sci., Vol. 375, Nos. 2-3, pp.L385-391.

25 http://gwyddion.net/.

26 Jackson, A.P., Vincent, J.F.V., Briggs, D., Crick, R.A., Davis, S.F., Hearn, M.J. and

Turner, R.M. (1986) J. Mater. Sci. Lett., Vol. 5, pp.975-978.

27 Jackson, A.P., Vincent, J.F.V. and Turner, R.M. (1989) Compos. Sci. Technol., Vol. 36, pp. $255-266$.

28 Sarikaya, M., Gunnison, K.E., Yasrebi, M. and Aksay, I.A. (1990) Mater. Res. Soc. Symp.

Proc., Vol. 174, pp.109-131.

29 Kotha, S.P., Li, Y. and Guzelsu, N. (2001) J. Mater. Sci., Vol. 36, pp.2001-2007.

30 Evans, A.G., Suo, Z., Wang, R.Z., Aksay, I.A., He, M.Y. and Hutchinson, J.W. (2001)

J. Mater. Res., Vol. 16, No. 9, pp.2475-2484.

31 Okumura, K. (2002) Eur. Phys. J. E, Vol. 7, pp.303-310.

32 Nukala, P.K.V.V. and Simunovic, S. (2005) Biomaterials, Vol. 26, pp.6087-6098.

33 Cortie, M.B., McBean, K.E. and Elcombe, M.M. (2006) Physica B, Vols. 385-386,

pp.545-547.

34 Barthelat, F., Tang, H., Zavattieri, P.D., Li, C-M. and Espinosa, H.D. (2007) J. Mech. Phys.

Solids, Vol. 55, pp.306-337.

35 Oliver, W.C. and Pharr, G.M. (1992) J. Mater. Res., Vol. 7, No. 4, pp.1564-1583.

36 Field, J.S. and Swain, M.V. (1993) J. Mater. Res., Vol. 8, No. 2, pp.297-306.

37 Gay, D. (2005) Hermes Lavoisier, ISBN 2-7462-1098-3, p.670.

38 Hibbitt, K. and Sorensen, I. (1997) HKS.

39 Bourrat, X., Francke, L., Lopez, E., Rousseau, M., Stempflé, Ph., Angellier, M. and Alberic, P. In line at CrystEngComm (Special issue, Lia Addadi, ed.)

$40 \mathrm{Wu}$, J., Herzog, W. and Epstein, M. (1998) J. Biomech., Vol. 31, pp.165-169.

41 Katti, D.R. and Katti, K.S. (2001) J. Mater. Sci., Vol. 36, pp.1411-1417.

42 Katti, D.R., Katti, K.S., Sopp, J.M. and Sarikaya, M. (2001) Comput. Theor. Polym. Sci.,

Vol. 11, pp.397-404.

43 Pantalé, O., Bacaria, J-L., Dalverny, O., Rakotomalala, R. and Caperaa, S. (2004)

Comp. Meth. App. Mech. Eng., Vol. 193, Nos. 39-41, pp.4383-4399. 